\title{
Effectiveness of an Educational Program in Enhancing Infertile Women's Psychological Health
}

\author{
Nagwa A. Souilm, ${ }^{1, *}$ Nawal Kamal Abd Elkhalek², Mervat Mohamed Hassan² \\ ${ }^{1}$ Psychiatric and Mental Health Nursing, Faculty of Nursing, South Valley University, Egypt \\ ${ }^{2}$ Obstetrics and Gynecological Nursing, Faculty of Nursing, South Valley University, Egypt \\ *Corresponding author: nagwamohamed@rocketmail.com
}

Received August 19, 2018; Revised October 13, 2018; Accepted October 28, 2018

\begin{abstract}
Background: Infertility is a worldwide problem with negative impacts on psychological health of couples. Nurses have a crucial role in the mitigation of these problems. Aim of the study: To examine the effectiveness of a nursing intervention in enhancing infertile women's psychological health and improving associated disorders. Subjects and methods: The study was conducted in the outpatient department at Qena General Hospital using a one-group quasi-experimental design. It involved 90 infertile women attending the setting for management. An interview questionnaire form with four scales namely the General Health Questionnaire (GHQ), Narcissistic Personality Inventory, Experiences of Close Relationships-Revised (ECR-R), and the Defensive Style Questionnaire (DSQ-60) was used in data collection. The researcher designed and implemented by the researchers in the light of the needs identified in the pre-intervention assessment phase. The study was achieved through assessment, planning, implementation, and evaluation phases. Results: Women' age ranged between 21 and 47 years, mostly with primary infertility (80.0\%). Statistically significant improvements were demonstrated at the post-intervention phase in all four domains of GHQ $(\mathrm{p}<0.001)$, and the mean total score increased from 39.6 to 68.0 $(\mathrm{p}<0.001)$. The total median narcissism personality score decreased from 24.50 before the intervention to 16.00 after the intervention $(\mathrm{p}<0.001)$. As for ECR-attachment scale, the median dropped from 4.16 to $3.11(\mathrm{p}<0.001)$. Similar statistically significant post-intervention improvements were revealed in the DSQ-60 scale. The multivariate analysis identified the study intervention as the main positive predictor of the GHQ score, a negative predictor of the narcissistic and ECR scores. Meanwhile, the study intervention was a positive predictor of the adapt DSQ domain whereas it was a negative predictor of the affect regulating domain score. Conclusion and recommendations: Infertile women suffer a number of psychological problems that are amenable to treatment through simple educational nursing interventions. Such educational endeavors should be implemented on a wide scale in all similar settings.
\end{abstract}

Keywords: infertility, GHQ, narcissistic personality, ECR-R, DSQ-60

Cite This Article: Nagwa A. Souilm, Nawal Kamal Abd Elkhalek, and Mervat Mohamed Hassan, "Effectiveness of an Educational Program in Enhancing Infertile Women’s Psychological Health.” American Journal of Nursing Research, vol. 6, no. 6 (2018): 515-523. doi: 10.12691/ajnr-6-6-20.

\section{Introduction}

Infertility rates vary between 8 and 12\% worldwide. [1] It is defined as the failure to achieve a clinical pregnancy after 12 months or more of regular unprotected sexual intercourse; it may be due to infectious, immunologic, biogenic, endocrine, or genetic causes [2,3], but often has no obvious cause. [4] However, the time needed to define infertility vary, so that comparisons of its rates by time and/or place is difficult. [5] A woman has primary infertility when she is unable to become pregnant or to carry a pregnancy to a live-birth, while having a previous pregnancy classifies her as having secondary infertility. [6,7] Technological advances now offer a number of approaches to deal with the problem and help infertile couples through assisted reproductive techniques (ART) such as In-vitro fertilization (IVF) using exogenous hormonal stimulation to induce final oocyte maturation, Intra-Uterine Insemination with or without hyper-stimulation, and Intra Cytoplasmic Sperm Injection. [8]

Infertility constitutes a major life crisis and could be associated with a narcissistic trauma increased with selfadmiration, self-centeredness, and self-regard, a type of neurosis characterized by a love of self that precedes, or even precludes love of others. [9] This could be a type of defense driven by feelings of guilt or shame whether conscious or unconscious. [10] Such psychological changes in the infertile woman decrease her ability to have normal relationships with others, and make her difficult to be satisfied. [11] This has to be considered in the management of the infertile woman. [12]

Infertility can have tremendous effects on couple's lives and psychological health; hence, it is a priority issue to be addressed in health care. Among other health care 
professionals, nurses and midwives are the team members who have the first encounter with the infertile woman while taking history and during initial assessment. As members of the reproductive health team, they have a crucial role in the management of infertility. [13] Their role in support, reassurance and training in coping techniques is of utmost importance in this life-shaking condition and overwhelming emotional reactions. Nonetheless, there is a paucity of research addressing the role of nursing interventions in dealing with the psychological disorders associated with infertility. [14] Stress reduction is needed to support these women's pursuit of conception. [15]

\subsection{Aim of the Study}

To examine the effectiveness of a nursing intervention in enhancing infertile women's psychological health and improving associated disorders. The research hypothesis was that the implementation of the nursing intervention will lead to significant improvements in infertile women's scores of General Health Questionnaire (GHQ), Narcissistic Personality Inventory, Experiences of Close Relationships-Revised (ECR-R), and Defensive Style Questionnaire (DSQ-60).

\section{Subjects and Methods}

\subsection{Research Design and Setting}

The study was conducted in the outpatient department at Qena General Hospital using a one-group quasi-experimental design with pre-post assessment. This general hospital provides charge-free inpatient and outpatient services. The work was done in the obstetrics department, located at the second floor of the hospital, with about 40 beds.

\subsection{Subjects}

The study involved 90 women attending the study setting for management of infertility. The inclusion criteria were being adult married woman with diagnosis of primary or secondary infertility. Those suffering chronic diseases were excluded. The sample size was calculated to demonstrate a post-intervention improvement in the scores of general health, narcissism, ECR, and DSQ scales with a moderate effect size (0.45) at 95\% level of confidence and $80 \%$ power. Accordingly, the required sample size is 79 women. This was increased to 90 women to compensate for an expected dropout rate of around $10 \%$.

\subsection{Data Collection Tools}

An interview questionnaire form was used in data collection. It included, in addition to a section for socio-demographic and medical characteristics, four scales namely the General Health Questionnaire (GHQ), Narcissistic Personality Inventory, Experiences of Close Relationships-Revised (ECR-R), and the Defensive Style Questionnaire (DSQ-60).

The socio-demographic section involved data about woman's age, education, job status, residence, family type, and income. The medical section asked about the details of woman's infertility such as age at marriage and its duration, the type, cause, and duration of infertility, family history, and the methods of contraception trials used.

General Health Questionnaire-28 (GHQ-28): The tool, developed by Goldberg [16] to screen for the risk of developing psychiatric disorders. It has 28 statements the GHQ-28 is a 28-item equally divided into four subscales, namely somatic symptoms, anxiety/insomnia, social dysfunction, and severe depression. The responses are on a 4-point scale (not at all, no more than usual, rather more than usual, and much more than usual), scored from zero to three, for a total scale score ranging between zero and 84. A total score 24 or higher is considered as distress. The tool has a high reliability with Cronbach's $\alpha$ 0.90-0.95 [17], and high validity. [18]

Narcissistic Personality Inventory (NPI): This 40-item tool was developed by Raskin and Hall [19] to measure non-clinical levels of the trait narcissism. It covers seven narcissistic component traits: Authority (8 items), Selfsufficiency (6 items), Superiority (5 items), Exhibitionism (7 items), Exploitativeness (5 items), Vanity (3 items), and Entitlement (6 items). The response to each item is dichotomous, either A or B. For scoring, one point is given to each item according to the tool key. The scores are summed-up so that a higher score indicates more trait intensity. The tool has good levels of validity and reliability. [20]

Experiences in Close Relationships-Revised (ECR-R) questionnaire: This tool was developed by Fraley et al [21] to assess individual's attachment. It is composed of 36 items equally categorized into avoidance and anxiety subscales. The responses are on a 7-point continuous Likert scale item ranging from strongly agree to strongly disagree. The scores from one to seven of each item are summed-up and divided by the number of items giving a mean score for each subscale and for the total scale. The scoring of some items is reversed so that a higher score indicates more avoidance or anxiety. The tool has documented validity and reliability. [22]

Defensive Style Questionnaire 60 (DSQ-60): This tool revised by Thygesen et al [23] is the most widely used tool in the assessment of defense mechanisms in psychology. It assesses 30 different defense mechanisms under three main categories, Adaptive, Image-distorting, and Affect-regulating. The adaptive category includes nine mechanisms as sublimation, rationalization, and humor; the image distorting has eleven defense mechanisms as fantasy, withdrawal, and intellectualization; lastly, the affect-regulating involves ten mechanisms as displacement, idealization, and helprejecting. Each of the 30 mechanisms is tested by two statements on a continuous 10-point scale. Their scores are added together for a maximum score of 20. For each of the three main categories, the scores of the underlying mechanisms are summed up to give a total score for the category. The tool has good validity and reliability. [24]

\subsection{Fieldwork}

The fieldwork was started immediately upon securing all necessary permissions and protocol approval. The tools used have already published high validity and reliability. Moreover, their reliability was tested in the current study, and they all showed high levels of reliability with Cronbach's 
alpha coefficients 0.99 for the GHQ scale, 0.77 for the Narcissistic scale, 0.94 for the ECR scale, and 0.87 for the DSQ scale.

The study was achieved through assessment, planning, implementation, and evaluation phases.

\subsubsection{Assessment Phase}

The researchers visited the setting and met with the medical and nursing directors to explain the aim and procedures of the study to gain their cooperation. Then, they started to meet with the infertile women individually in the waiting area, explained to them the aim and process of the study. Those who were eligible were invited to participate. The woman who gave her verbal informed consent was interviewed individually using the prepared data collection form. The individual interview lasted from 60-90 minutes for each woman.

\subsubsection{Planning Phase}

The program was designed by the researchers in the light of the needs identified in the pre-intervention assessment phase. The aim was to enhance infertile women's psychological health. It was planned to fill the knowledge and practice gaps identified. The program covered brief information on infertility, with more emphasis on the psychological aspects such as the relaxation techniques, exercise, stress and anger management, patterns of adjustments, in addition to communication skills.

\subsubsection{Implementation Phase}

Once the program was finalized, it was implemented over 18 sessions: four theoretical and 14 practical. The first two sessions were for acquaintance, identifying program objectives, content, and procedures, in addition to pre-testing. In the following three sessions were an overview of the psychosocial problems associated with infertility, negative distress, and coping strategies. Sessions 6 and 7 were dedicated to finding and achieving goals and sessions 8 and 9 to self-conversation and physical pressure. The sessions from 10 to 12 covered family pressure, stress from family, and adjustment, while the sessions from 13 to 15 were for pressures and relaxation techniques, and sessions $17-18$ for diet and exercise. The last session was for overall feedback and post-testing. The durations of the sessions varied from 60 to 90 minutes. Women were divided into small groups, and the researchers met with each group twice per week from 8:30 am to 12:00 pm.

\subsubsection{Evaluation Phase}

The effectiveness of the intervention program was evaluated after completion of the training sessions. This was done using the same data collection form and procedure.

\subsection{Statistical Analysis}

Data entry and statistical analysis were done using SPSS 20.0 statistical software package. Data were presented using descriptive statistics in the form of frequencies and percentages for qualitative variables, and means and standard deviations and medians for quantitative variables. Cronbach alpha coefficient was calculated to assess the reliability of the scales used through their internal consistency. Quantitative continuous data were compared using the non-parametric Mann-Whitney test. Qualitative categorical variables were compared using chi-square test. In order to identify the independent predictors of the various scale' scores, multiple linear regression analysis was used and analysis of variance for the full regression models done. Statistical significance was considered at p-value $<0.05$.

\section{Results}

Women' age ranged between 21 and 47 years, median 30.0 as shown in Table 1. Approximately a half of them had secondary education (47.8\%), with equal percentages of illiterate and university grads (18.9\%). Around two-thirds were housewives (62.2\%) and from rural area (62.2\%), with a majority having sufficient income (80.0\%).

Table 2 indicates that more than half of the women married a age 20 - 30 years (56.7\%), had less than 10 -year marriage duration (62.2\%), and more than 6-year infertility duration (54.4\%). Their infertility was mostly primary $(80.0 \%)$ with a known cause, mostly ovarian (60.9\%), and $53.3 \%$ of them had positive family history. The most common method of conception trial was ovulation induction (72.2\%).

Examining women's General Health (Table 3) demonstrates that around a half of them were having distress in all four domains before the intervention, the highest being in the somatic domain (50.0\%). Statistically significant improvements were demonstrated at the post-intervention phase in all four domains $(\mathrm{p}<0.001)$, and the mean total score increased from 39.6 to $68.0(\mathrm{p}<0.001)$.

Table 1. Socio-demographic characteristics of women in the study sample $(\mathbf{n}=90)$

\begin{tabular}{|c|c|c|}
\hline & Frequency & Percent \\
\hline Age: & & \\
\hline$<35$ & 63 & 70.0 \\
\hline $35+$ & 27 & 30.0 \\
\hline Range & \multicolumn{2}{|c|}{$21.0-47.0$} \\
\hline Mean \pm SD & \multicolumn{2}{|c|}{$30.7 \pm 5.7$} \\
\hline Median & \multicolumn{2}{|c|}{30.0} \\
\hline Education: & & \\
\hline Non & 17 & 18.9 \\
\hline Basic & 13 & 14.4 \\
\hline Secondary & 43 & 47.8 \\
\hline University & 17 & 18.9 \\
\hline \multicolumn{3}{|l|}{ Job: } \\
\hline Housewife & 56 & 62.2 \\
\hline Working & 34 & 37.8 \\
\hline \multicolumn{3}{|l|}{ Residence: } \\
\hline Urban & 34 & 37.8 \\
\hline Rural & 56 & 62.2 \\
\hline \multicolumn{3}{|l|}{ Family type: } \\
\hline Nuclear & 46 & 51.1 \\
\hline Extended & 44 & 48.9 \\
\hline \multicolumn{3}{|l|}{ Income: } \\
\hline Insufficient & 18 & 20.0 \\
\hline Sufficient & 72 & 80.0 \\
\hline
\end{tabular}


Table 2. Infertility characteristics of women in the study sample $(\mathbf{n}=90)$

\begin{tabular}{|c|c|c|}
\hline & Frequency & Percent \\
\hline Age at marriage: & & \\
\hline$<20$ & 39 & 43.3 \\
\hline $20-30$ & 51 & 56.7 \\
\hline Marriage duration: & & \\
\hline$<10$ & 56 & 62.2 \\
\hline $10+$ & 34 & 37.8 \\
\hline Infertility years: & & \\
\hline$<6$ & 41 & 45.6 \\
\hline $6+$ & 49 & 54.4 \\
\hline Infertility type: & & \\
\hline Primary & 72 & 80.0 \\
\hline Secondary & 18 & 20.0 \\
\hline Fertility cause: & & \\
\hline Unknown & 26 & 28.9 \\
\hline Known: & 64 & 71.1 \\
\hline Cause (n=64): & & \\
\hline Ovarian & 39 & 60.9 \\
\hline Tubal & 20 & 31.3 \\
\hline Uterine & 5 & 7.8 \\
\hline Family history: & & \\
\hline Yes & 48 & 53.3 \\
\hline No & 42 & 46.7 \\
\hline Methods of conception trials:@ & & \\
\hline Ovulation induction & 65 & 72.2 \\
\hline LOD & 25 & 27.8 \\
\hline IVF & 16 & 17.8 \\
\hline ICSI & 14 & 15.6 \\
\hline
\end{tabular}

Table 4 illustrates statistically significant post-intervention decreases in women's scores of narcissistic personality. This was evident in all its domains, with the exception of exhibitionism which significantly increased $(\mathrm{p}=0.03)$, and superiority which did not significantly change $(p=0.500)$. The total median narcissism personality score decreased from 24.50 before the intervention to 16.00 after the intervention $(\mathrm{p}<0.001)$. As regards ECR-attachment scale, the same table shows statistically significant decreases in its anxiety and avoidance domains, as well as in the total scale score, where the median dropped from 4.16 to 3.11 $(\mathrm{p}<0.001)$.

Concerning the DSQ-60 scale, Table 5 indicates statistically significant post-intervention increases in most of its adaptive domains. The only exceptions were in self-observation, which significantly decreased $(p=0.006)$, while the reaction formation and self-assertion did not significantly change. In total, the adaptive median score increased from 92.00 to $104.00(p<0.001)$. As regards the affect regulating domains, they all demonstrated statistically significant post-intervention decreases with the exception of suppression which increased $(\mathrm{p}<0.001)$, and dissociation and intellectualization which did not significantly change. The total affect regulating median score did not also significantly change $(p=0.30)$. Similarly, the image-distorting domains showed statistically significant post-intervention decreases. The only exceptions were in displacement and undoing, which significantly increased, and the splitting self which did not significantly change $(p=0.13)$. In total, the image-distorting median score dropped from 101.50 to $89.50(\mathrm{p}<0.001)$.

The multivariate analysis (Table 6) identified the study intervention as the main positive predictor of the GHQ score in addition to woman's age, while the rural residence was a negative predictor. As for the narcissistic score, the GHQ score in addition to the study intervention and having a known cause fertility were its negative predictors. Lastly, the study intervention was the only negative predictor of the ECR score, while income was a positive predictor.

Concerning the DSQ score, Table 7 shows that the study intervention, age, income, infertility duration, and known cause infertility were the positive predictor of the adapt domain. Conversely, the working status and marriage duration were negative predictors. As for the affect regulating domain, the study intervention was its negative predictor, whereas the income and infertility duration were positive predictors. The same latter predictors were also identified for the score of the image distorting domain.

Table 3. Women's General Health before and after the intervention

\begin{tabular}{|c|c|c|c|c|c|c|}
\hline \multirow{3}{*}{ GHQ } & \multicolumn{4}{|c|}{ Time } & \multirow{3}{*}{$\mathrm{X}^{2}$ test } & \multirow{3}{*}{ p-value } \\
\hline & \multicolumn{2}{|c|}{ Pre $(n=90)$} & \multicolumn{2}{|c|}{ Post (n=90) } & & \\
\hline & No. & $\%$ & No. & $\%$ & & \\
\hline $\begin{array}{l}\text { Somatic symptoms: } \\
\text { Distress } \\
\text { No distress }\end{array}$ & $\begin{array}{l}45 \\
45\end{array}$ & $\begin{array}{l}50.0 \\
50.0\end{array}$ & $\begin{array}{c}1 \\
89\end{array}$ & $\begin{array}{c}1.1 \\
98.9\end{array}$ & 56.53 & $<0.001^{*}$ \\
\hline $\begin{array}{l}\text { Insomnia/anxiety: } \\
\text { Distress } \\
\text { No distress }\end{array}$ & $\begin{array}{l}39 \\
51\end{array}$ & $\begin{array}{l}43.3 \\
56.7\end{array}$ & $\begin{array}{c}1 \\
89\end{array}$ & $\begin{array}{c}1.1 \\
98.9 \\
\end{array}$ & 46.41 & $<0.001^{*}$ \\
\hline $\begin{array}{l}\text { Social dysfunction: } \\
\text { Distress } \\
\text { No distress } \\
\end{array}$ & $\begin{array}{l}33 \\
57 \\
\end{array}$ & $\begin{array}{l}36.7 \\
63.3 \\
\end{array}$ & $\begin{array}{c}1 \\
89 \\
\end{array}$ & $\begin{array}{c}1.1 \\
98.9 \\
\end{array}$ & 37.13 & $<0.001^{*}$ \\
\hline $\begin{array}{l}\text { Depression: } \\
\text { Distress } \\
\text { No distress }\end{array}$ & $\begin{array}{l}40 \\
50\end{array}$ & $\begin{array}{l}44.4 \\
55.6\end{array}$ & $\begin{array}{c}0 \\
90\end{array}$ & $\begin{array}{c}0.0 \\
100.0\end{array}$ & 51.43 & $<0.001 *$ \\
\hline $\begin{array}{l}\text { Total GHQ: } \\
\text { Distress } \\
\text { No distress }\end{array}$ & $\begin{array}{l}40 \\
50\end{array}$ & $\begin{array}{l}44.4 \\
55.6\end{array}$ & $\begin{array}{c}1 \\
89\end{array}$ & $\begin{array}{c}1.1 \\
98.9\end{array}$ & 48.04 & $<0.001^{*}$ \\
\hline Total score & & & & & & \\
\hline $\begin{array}{l}\text { Mean } \pm \text { SD } \\
\text { Median }\end{array}$ & & & & & & \\
\hline
\end{tabular}

(*) Statistically significant at $\mathrm{p}<0.05$, (U) Mann Whitney test. 
Table 4. Scores of women's Narcissistic Personality Inventory and Relationships-Revised (ECR-R) before and after the intervention

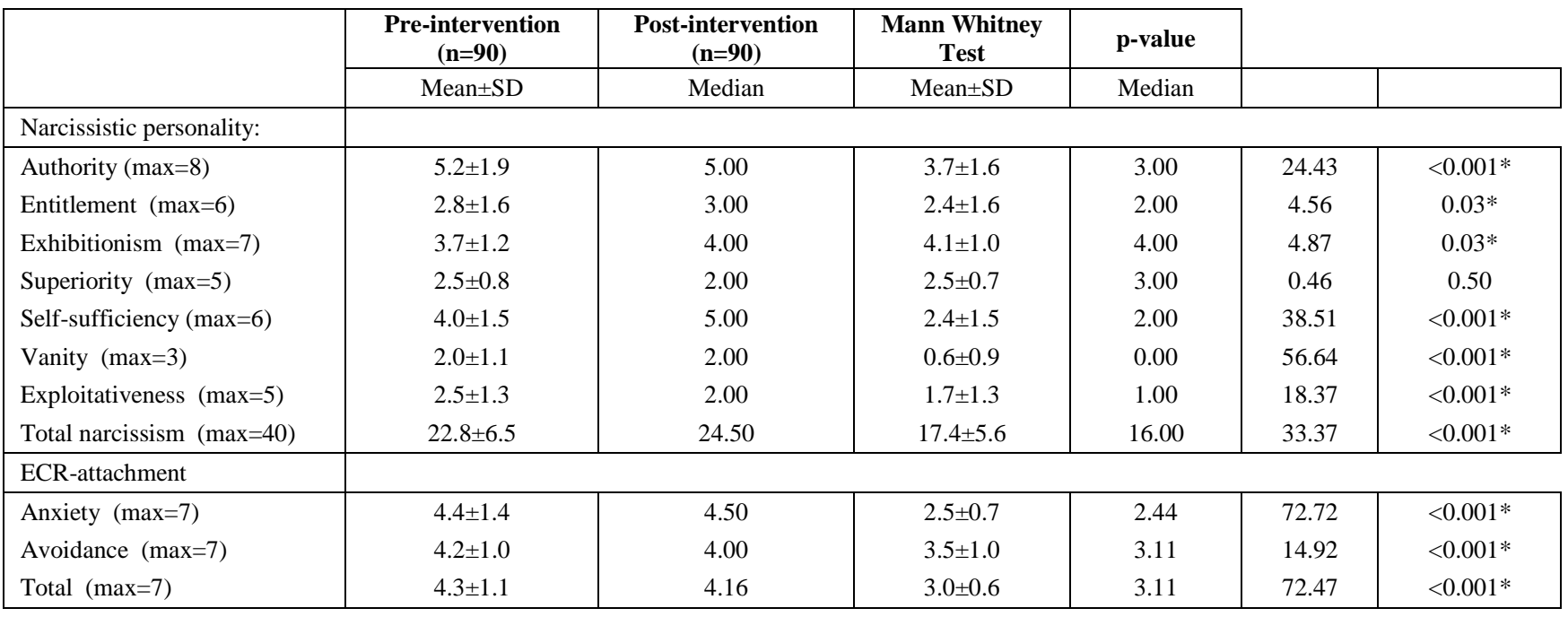

$\left(^{*}\right)$ Statistically significant at $\mathrm{p}<0.05$.

Table 5. Scores of women's DSQ-60 before and after the intervention

\begin{tabular}{|c|c|c|c|c|c|c|}
\hline \multirow{2}{*}{ DSQ-60 } & \multicolumn{2}{|c|}{$\begin{array}{c}\text { Pre-intervention } \\
(\mathrm{n}=90)\end{array}$} & \multicolumn{2}{|c|}{$\begin{array}{c}\text { Post-intervention } \\
(\mathrm{n}=\mathbf{9 0})\end{array}$} & \multirow{2}{*}{$\begin{array}{c}\text { Mann Whitney } \\
\text { Test }\end{array}$} & \multirow[t]{2}{*}{ p-value } \\
\hline & Mean \pm SD & Median & Mean \pm SD & Median & & \\
\hline \multicolumn{7}{|l|}{ Adaptive $(\max =18)$} \\
\hline Altruism & $10.1 \pm 3.9$ & 10.00 & $13.5 \pm 3.0$ & 14.00 & 32.27 & $<0.001^{*}$ \\
\hline Sublimation & $10.1 \pm 3.9$ & 10.00 & $14.7 \pm 2.3$ & 15.00 & 62.53 & $<0.001^{*}$ \\
\hline Rationalization & $10.0 \pm 2.4$ & 10.00 & $11.4 \pm 3.1$ & 10.00 & 8.91 & $0.003 *$ \\
\hline Humor & $10.5 \pm 4.4$ & 11.00 & $12.8 \pm 4.2$ & 12.50 & 14.06 & $<0.001^{*}$ \\
\hline Reaction formation & $9.9 \pm 3.8$ & 10.00 & $10.3 \pm 4.2$ & 12.00 & 0.80 & 0.37 \\
\hline Self-observation & $11.9 \pm 3.6$ & 12.00 & $10.1 \pm 4.2$ & 10.50 & 7.47 & $0.006^{*}$ \\
\hline Self-assertion & $9.5 \pm 3.7$ & 10.00 & $10.3 \pm 4.1$ & 10.50 & 1.31 & 0.25 \\
\hline Omnipotence & $9.3 \pm 3.3$ & 10.00 & $10.4 \pm 3.0$ & 11.00 & 4.79 & $0.03 *$ \\
\hline Anticipation & $10.9 \pm 3.0$ & 10.00 & $12.7 \pm 3.5$ & 11.00 & 13.21 & $<0.001 *$ \\
\hline Total $(\max =162)$ & $92.2 \pm 22.1$ & 92.00 & $106.2 \pm 10.3$ & 104.00 & 17.10 & $<0.001^{*}$ \\
\hline \multicolumn{7}{|c|}{ Affect regulating $(\max =18)$} \\
\hline Suppression & $10.4 \pm 4.4$ & 10.00 & $13.3 \pm 2.4$ & 13.00 & 14.76 & $<0.001^{*}$ \\
\hline Denial & $10.0 \pm 3.5$ & 10.00 & $7.9 \pm 3.8$ & 9.00 & 12.42 & $<0.001^{*}$ \\
\hline Devaluation other & $9.6 \pm 2.9$ & 10.00 & $7.8 \pm 3.3$ & 9.00 & 13.91 & $<0.001^{*}$ \\
\hline Dissociation & $10.1 \pm 2.8$ & 10.00 & $10.2 \pm 4.0$ & 10.00 & 0.07 & 0.80 \\
\hline Devaluation self & $9.2 \pm 3.2$ & 9.00 & $7.4 \pm 3.0$ & 8.00 & 11.56 & $0.001 *$ \\
\hline Fantasy & $8.9 \pm 3.5$ & 8.50 & $7.4 \pm 4.0$ & 6.00 & 6.48 & $0.01 *$ \\
\hline Withdrawal & $8.9 \pm 3.3$ & 9.00 & $6.9 \pm 2.9$ & 6.00 & 13.28 & $<0.001 *$ \\
\hline Intellectualization & $10.0 \pm 3.5$ & 10.00 & $10.4 \pm 2.5$ & 10.00 & 0.47 & 0.49 \\
\hline Repression & $10.9 \pm 3.9$ & 10.00 & $8.1 \pm 4.1$ & 6.50 & 17.95 & $<0.001^{*}$ \\
\hline Isolation & $11.0 \pm 4.0$ & 10.00 & $7.3 \pm 3.5$ & 6.00 & 34.50 & $<0.001^{*}$ \\
\hline Affiliation & $10.9 \pm 4.7$ & 11.00 & $15.6 \pm 2.9$ & 17.00 & 49.23 & $<0.001^{*}$ \\
\hline Total $(\max =198)$ & $109.9 \pm 25.1$ & 106.00 & $102.4 \pm 19.1$ & 106.00 & 1.06 & 0.30 \\
\hline \multicolumn{7}{|c|}{ Image-distorting $(\max =18)$} \\
\hline Passive aggression & $8.4 \pm 3.5$ & 9.00 & $6.3 \pm 3.3$ & 4.00 & 14.61 & $<0.001 *$ \\
\hline Splitting other & $9.3 \pm 3.1$ & 9.00 & $7.2 \pm 2.8$ & 6.00 & 17.62 & $<0.001^{*}$ \\
\hline Projection & $10.6 \pm 4.0$ & 11.00 & $5.5 \pm 3.0$ & 4.00 & 60.81 & $<0.001^{*}$ \\
\hline Projective identification & $10.6 \pm 3.7$ & 10.00 & $8.5 \pm 3.7$ & 10.00 & 9.96 & $0.002 *$ \\
\hline Acting out & $10.9 \pm 3.4$ & 10.00 & $8.4 \pm 3.9$ & 9.00 & 13.52 & $<0.001^{*}$ \\
\hline Splitting self & $9.6 \pm 3.7$ & 10.00 & $8.7 \pm 4.3$ & 10.00 & 2.25 & 0.13 \\
\hline Displacement & $10.4 \pm 4.3$ & 10.00 & $11.8 \pm 2.3$ & 11.00 & 6.09 & $0.01^{*}$ \\
\hline Idealization & $10.5 \pm 3.0$ & 10.00 & $8.7 \pm 4.3$ & 9.00 & 9.71 & $0.002^{*}$ \\
\hline Help rejecting & $9.1 \pm 3.8$ & 10.00 & $7.8 \pm 3.7$ & 9.50 & 4.27 & $0.04 *$ \\
\hline Undoing & $10.6 \pm 3.2$ & 10.00 & $13.5 \pm 3.8$ & 13.00 & 26.28 & $<0.001 *$ \\
\hline Total $(\max =180)$ & $100.1 \pm 22.1$ & 101.50 & $86.4 \pm 12.9$ & 89.50 & 29.42 & $<0.001^{*}$ \\
\hline
\end{tabular}

$(*)$ Statistically significant at $\mathrm{p}<0.05$. 
Table 6. Best fitting multiple linear regression model for the GHQ, narcissistic and ECR scores

\begin{tabular}{|c|c|c|c|c|c|c|c|}
\hline & \multicolumn{2}{|c|}{$\begin{array}{l}\text { Unstandardized } \\
\text { Coefficients }\end{array}$} & \multirow{2}{*}{$\begin{array}{l}\text { Standardized } \\
\text { Coefficients }\end{array}$} & \multirow[t]{2}{*}{ t-test } & \multirow[t]{2}{*}{ p-value } & \multicolumn{2}{|c|}{$\begin{array}{l}\text { 95\% Confidence } \\
\text { Interval for B }\end{array}$} \\
\hline & B & Std. Error & & & & Lower & Upper \\
\hline \multicolumn{8}{|l|}{ GHQ score } \\
\hline Constant & 23.66 & 4.41 & & 5.369 & $<0.001$ & 14.94 & 32.39 \\
\hline Intervention & 14.97 & 1.23 & 0.72 & 12.217 & $<0.001$ & 12.54 & 17.39 \\
\hline Age & 0.35 & 0.11 & 0.19 & 3.159 & 0.002 & 0.13 & 0.56 \\
\hline Rural residence & -2.92 & 1.24 & -0.14 & 2.359 & 0.020 & -5.37 & -0.47 \\
\hline \multicolumn{8}{|c|}{$\begin{array}{lc}\text { r-square }=0.56 & \text { Model ANOVA: } F=54.90, p<0.001 \\
\text { Variables entered and excluded: education, job, income, marriage age }\end{array}$} \\
\hline \multicolumn{8}{|l|}{ Narcissistic score } \\
\hline Constant & 23.57 & 2.47 & & 9.532 & $<0.001$ & 18.68 & 28.47 \\
\hline Intervention & -2.53 & 1.28 & -0.19 & 1.987 & 0.049 & -5.06 & -0.01 \\
\hline Known cause & -3.24 & 1.09 & -0.20 & 2.969 & 0.004 & -5.40 & -1.08 \\
\hline GHQ score & -0.31 & 0.06 & -0.49 & 5.009 & $<0.001$ & -0.43 & -0.19 \\
\hline \multicolumn{8}{|c|}{$\begin{array}{ll}\mathrm{r} \text {-square }=0.44 & \text { Model ANOVA: } \mathrm{F}=33.17, \mathrm{p}<0.001 \\
\text { Variables entered and excluded: age, education, job, income, residence, marriage age and duration, infertility type, years, family history }\end{array}$} \\
\hline \multicolumn{8}{|l|}{ ECR score } \\
\hline Constant & 272.43 & 29.80 & & 9.143 & $<0.001$ & 213.44 & 331.42 \\
\hline Intervention & -47.35 & 5.13 & -0.63 & 9.237 & $<0.001$ & -57.50 & -37.20 \\
\hline Income & 9.51 & 4.00 & 0.16 & 2.375 & 0.019 & 1.58 & 17.43 \\
\hline
\end{tabular}

Table 7. Best fitting multiple linear regression model for the DSQ domains scores

\begin{tabular}{|c|c|c|c|c|c|c|c|}
\hline & \multicolumn{2}{|c|}{$\begin{array}{l}\text { Unstandardized } \\
\text { Coefficients }\end{array}$} & \multirow{2}{*}{$\begin{array}{c}\text { Standardized } \\
\text { Coefficients }\end{array}$} & \multirow[t]{2}{*}{ t-test } & \multirow[t]{2}{*}{ p-value } & \multicolumn{2}{|c|}{$\begin{array}{l}\text { 95\% Confidence } \\
\text { Interval for B }\end{array}$} \\
\hline & B & Std. Error & & & & Lower & Upper \\
\hline \multicolumn{8}{|l|}{ Adaptation } \\
\hline Constant & 8.41 & 17.70 & & 0.475 & 0.636 & -26.64 & 43.46 \\
\hline Intervention & 10.32 & 2.66 & 0.28 & 3.885 & $<0.001$ & 5.06 & 15.58 \\
\hline Age & 0.76 & 0.32 & 0.23 & 2.362 & 0.020 & 0.12 & 1.39 \\
\hline Working & -6.05 & 2.98 & -0.16 & 2.033 & 0.044 & -11.95 & -0.16 \\
\hline Income & 4.90 & 2.31 & 0.18 & 2.124 & 0.036 & 0.33 & 9.47 \\
\hline Marriage duration & -11.36 & 4.33 & -0.30 & 2.623 & 0.010 & -19.94 & -2.78 \\
\hline Infertility duration & 10.58 & 2.35 & 0.45 & 4.493 & $<0.001$ & 5.91 & 15.24 \\
\hline Known cause & 6.93 & 3.36 & 0.15 & 2.065 & 0.041 & 0.28 & 13.58 \\
\hline \multicolumn{8}{|c|}{ Model ANOVA: $\mathrm{F}=8.93, \mathrm{p}<0.001$} \\
\hline \multicolumn{8}{|l|}{ Affect regulating } \\
\hline Constant & 99.60 & 9.46 & & 10.528 & $<0.001$ & 80.87 & 118.33 \\
\hline Intervention & -10.89 & 4.30 & -0.21 & 2.534 & 0.013 & -19.40 & -2.38 \\
\hline Income & 9.61 & 3.31 & 0.24 & 2.902 & 0.004 & 3.05 & 16.16 \\
\hline Infertility duration & 7.11 & 2.78 & 0.21 & 2.561 & 0.012 & 1.61 & 12.60 \\
\hline \multicolumn{8}{|c|}{$\begin{array}{ll}\text { r-square }=0.14 & \text { Model ANOVA: } F=7.87, p<0.001 \\
\text { Variables entered and excluded: age, education, job, residence, marriage age and duration, infertility type, family history }\end{array}$} \\
\hline \multicolumn{8}{|l|}{ Image distorting } \\
\hline Constant & 94.01 & 7.16 & & 13.131 & $<0.001$ & 79.84 & 108.18 \\
\hline Intervention & -18.54 & 3.25 & -0.42 & 5.701 & $<0.001$ & -24.98 & -12.10 \\
\hline Income & 6.63 & 2.51 & 0.20 & 2.647 & 0.009 & 1.67 & 11.59 \\
\hline Infertility duration & 9.68 & 2.10 & 0.34 & 4.611 & $<0.001$ & 5.53 & 13.84 \\
\hline
\end{tabular}

\section{Discussion}

The study findings indicate that infertile women had generally low scores of General Health, and high scores of Narcissistic Personality, Experiences of Close Relationships-Revised, and Defensive Style. These demonstrated significant improvements after implementation of the nursing intervention, which leads to acceptance of the set research hypothesis.

The present study involved a sample of infertile women with average socioeconomic level as indicated by their mostly intermediate level education, unemployment, and 
rural residence. Their median age was thirty years, a typical age of decline of fertility as highlighted by Tamparo and Lewis [25] who mentioned that women's fertility peaks at the age 24 , and then declines by age 30 . The majority were having sufficient income, and this expected since the new technological approaches to assisted fertilization are expensive. In this regard, Gleicher [26] emphasized the importance of looking for more affordable infertility treatment approaches.

The majority of the women in the current were having primary infertility, i.e. they never got a live birth. This is in congruence with previous reports that indicate that primary infertility outnumbers secondary infertility, e.g. in a recent study in Morocco where the rate of primary infertility was more than a double of secondary infertility. [27] However, in discordance with the literature, most of the cases of infertility in the present study sample were of known causes. [28] This might be explained by the possibility of a selection bias given that the study setting may provide treatment for such underlying causes as the ovarian, tubal, or uterine treatable disorders.

More than a half of the women in the present study sample had their infertility for more than six years. This is accompanied by many trials of a wide variety of assisted conception methods as shown in the study results. The findings demonstrate how much women or couples are perseverant and determined in their pursuit of having an offspring. Moreover, the duration of infertility was identified as a significant predictor of the woman' DSQ scores in all three domains, indicating that such defense mechanisms grow-up as the duration of infertility extends. The finding is in congruence with Rashidi et al [29] whose study in Iran demonstrated a significant association between infertile women's defense mechanism and the duration of infertility.

According to the present study findings, approximately one-half of the infertile women were having distress based on their General Health scores. This reflects high prevalence of somatic symptoms, anxiety, insomnia, depression, and social dysfunction. Such symptoms are explained by the woman's internal feelings of guilt for not being able to fulfill a main feminine role, and this is superimposed by the social pressures of a society considering infertility as a shame rather than an actual illness. The findings are in agreement with those of Namdar et al [30] whose study in Iran revealed that more than half of infertile women had high GHQ scores indicating distress.

The implementation of the current study intervention was associated with marked improvement in infertile women's General Health, with only one of them still having distress at the post-intervention phase. The effect of the intervention was confirmed by multivariate analysis that identified it as the main positive predictor of the GHQ score. Meanwhile, the older age women and those of rural residence benefited less from the intervention compared with the younger ones residing in urban areas. This might be attributed to the feeling of having more chance to conceive among the younger ones, and the higher social burdens posed on those residing in rural areas. Similar success of psychological interventions aimed at improving the coping of infertile women and relieving their distress were reported in two studies in Iran. [31,32]
Concerning the narcissistic personality, the current study results revealed generally high pre-intervention scores in most of its domains. This reflects infertile women's response to their inability to conceive by trying to invest onto the self in order to regulate their self-esteem. Thus, they tended to have high scores in domains of entitlement, vanity, and exploitativeness. In agreement with this, Poddar [33] found that infertile of women are significantly more narcissistic in comparison with fertile ones, and attributed this to using narcissism as a defense. They tend to cover their feeling of insufficiency by higher level of authority, self-sufficiency, and superiority thinking that this might compensate for the lack of social acceptance they feel. Furthermore, infertile women may consider infertility as injustice, which leads them to react defensively. [34]

The present study intervention led to significant improvements in infertile women's scores of narcissistic personality. This was of more importance in the narcissistic domains of concern such as vanity, entitlement, and exploitativeness. However, the total score showed a significant decrease, and this was also attributed to the implementation of the intervention, which was identified as its main negative predictor. In addition, the GHQ score was another negative predictor of the narcissism score, indicating an additional indirect effect of the intervention on it. An additional factor negatively affecting the improvement in the narcissism score was that of having fertility of known cause. This might be explained by that women with fertility of unknown cause do suffer more psychological troubles, and thus could have get more benefit from the intervention due to their more need for it. In agreement with this, @@Dada et al [35] highlighted that unexplained infertility is emotionally more stressful to women given the obscure management plan.

The current study has also addressed infertile women's experiences in close relationships (ECR-R). The results indicated that they had high scores in both of its anxiety and avoidance domains before the intervention. This reflects woman' fears of losing her marital life because of her inability to perceive, and the changes in her partner's emotions. In this context, a study in the United States revealed that the highest priority of the majority of infertile couples were the maintenance of a stable and satisfying marital relationships. [36]

Additionally, the high scores of the avoidant aspect of the ECR-R scale could be a reflection of the present study woman's attitude towards the society, which always blames the infertile woman for this condition. In agreement with this, a study in Sweden revealed that many of the infertile women, particularly those with secondary infertility were avoidant in the discussion of fertilityrelated issues in their social encounters, but to a less extent with their spouses. [37]

Meanwhile, the implementation of the intervention program led to significant decreases in the scores of both domains and in the total ECR score. The role of the intervention in this improvement was confirmed by multivariate analysis, which identified it as a negative predictor. This could be attributed to the content and process of the intervention, which responded to women's unmet needs. A similar success of a nursing care intervention in reducing the anxiety of infertile women was reported in a study in China. [38] 
Lastly, the infertile women's defenses were evaluated and addressed in the present study. The findings revealed post-intervention improvements in all its three main domains, with significant increases in the adaptation domain, and significant decreases in the image-distorting domain. Although the bivariate analysis could not demonstrate a significant change in the affect regulating domain, the study intervention was identified as a significant independent negative predictor for it. This was also true for the image distorting domain, while the intervention was a positive predictor of the score of the adaptive domain. Therefore, the implementation of the study intervention enhanced the infertile women's positive defenses and reduced their negative defenses. In this respect, Rashidi et al [29] clarified that a negative or immature defense mechanism is the one leading to maladaptive behavior negatively affecting a person physical/mental health.

\section{Conclusion and Recommendations}

The study concludes that infertile women suffer a number of psychological problems that are amenable to treatment through simple educational nursing interventions. Therefore, such educational endeavors should be implemented on a wide scale in all settings providing services to these women provided that they are based on identified unmet needs.

\section{References}

[1] Vander Borght M., and Wyns C. (2018). Fertility and infertility: Definition and epidemiology. Clin Biochem. 2018 Mar 16. pii: S0009-9120(18)30220-0.

[2] Altmäe S., Stavreus-Evers A., Ruiz J.R., Laanpere M., Syvänen T., Yngve A., Salumets A., Nilsson T.K. (2010). "Variations in folate pathway genes are associated with unexplained female infertility". Fertility and Sterility. 94 (1): 130-137.

[3] Assisted Conception Taskforce [ACT], (2014). Trying to have a baby. Your step-by-step guide to assistedconception. Available online: http://www.assistedconception.net/resources/ACT_Ratgeber.pdfdo wnloaded $11 / 4 /$.

[4] WHO (2013). World Health Organization. Infertility. 2013.

[5] Gurunath S., Pandian Z., Anderson R.A., and Bhattacharya S. (2011). "Defining infertility--a systematic review of prevalence studies". Human Reproduction Update.; 17 (5): 575-88.

[6] Maya N. et al., (2012). National, regional, and global trends in infertility of 227 health survey. Published. December 18, 2012.

[7] GBD (2015). Disease and Injury Incidence and Prevalence, Collaborators. (8 October 2016). "Global, regional, and national incidence, prevalence, and years lived with disability for 310 diseases and injuries, 1990-2015: a systematic analysis for the Global Burden of Disease Study 2015". Lancet.; 388 (10053): 1545-1602.

[8] Abbara A., Clarke S.A., and Dhillo W.S. (2012). Novel concepts for inducing final oocyte maturation in IVF (In Vitro Fertilization) Treatment. Endocr Rev. 2018 Jul 2.

[9] Mayo Clinic Staff (2017). "Narcissistic personality disorder Symptoms \& causes", Mayo Clinic, Mayo Foundation for Medical Education and Research, retrieved June 28, 2018

[10] Gerald Alper (2003). Self Defence in a Narcissistic World p. 10.

[11] Narcissistic Personality Disorder (2017). In: Diagnostic and Statistical Manual of Mental Disorders DSM-5. 5th ed. Arlington, Va.: American Psychiatric Association; 2013. http://dsm.psychiatryonline.org. Accessed Sept. 25.

[12] Ronningstam E. (2010). Narcissistic personality disorder: a current review. Curr Psychiatr Rep.; 12: 68-75.
[13] Shahnaz Anwar1 et al., (2016). Infertility: A Review on Causes, Treatment and Management This article was published in the following Scient Open Access Journal: Women's Health \& Gynecology Received May 20, 2016; Accepted June 10, 2016; Published June 16, 2016.

[14] Kenneth I.A., Philip J.U., Timothy G. J., Alan H., Bradley R.C., Andrew D.S., and Douglas T.C. (2015). "Aberrant sperm DNA methylation predicts male fertility status and embryo quality". Fertility and Sterility; 104 (6): 1388-1397.

[15] Domar A.D., Rooney K., Hacker M.R., Sakkas D., and Dodge L.E. (2018). Burden of care is the primary reason why insured women terminate in vitro fertilization treatment. Fertil Steril.; 109(6): 1121-1126.

[16] Goldberg D. (1978). Manual of the General Health Questionnaire. Windsor: NFER-Nelson.

[17] Failde I. and Ramos R. (2000). Comparison between the GHQ-28 and SF-36 (MH 1-5) for the assessment of the mental health in patients with Ischemic heartdisease. Eur J Epidemiol; 16:311.

[18] Sakakibara B.M., Miller W.C., Orenczuk S.G., Wolfe D.L., Team S.R. (2009). A systematic review of depression and anxiety measures used with individuals with spinal cord injury. Spinal Cord; 47(12): 841-51.

[19] Raskin R.N. and Calvin S.H. (1979). “A Narcissistic Personality Inventory.” Psychological Reports; 45.2 (1979): 590-590.

[20] Ackerman R.A., Witt E.A., Donnellan M.B., Trzesniewski K.H., Robins R.W., and Kashy D.A. (2011). What Does the Narcissistic Personality Inventory Really Measure? Assessment; 18(1) 67-87.

[21] Fraley R. C., Waller N. G., and Brennan K. A. (2000). An item-response theory analysis of self-report measures of adult attachment. Journal of Personality and Social Psychology; 78: 350-365.

[22] Fraley R. C. (2002). Attachment stability from infancy to adulthood: Meta-analysis and dynamic modeling of development mechanisms. Personality and Social Psychology Review; 6: 123-151.

[23] Thygesen K. L., Drapeau M., Trijsburg R. W., Lecours S., and de Roten Y. (2008). Assessing defense styles: Factor structure and psychometric properties of the new Defense Style Questionnaire 60 (DSQ-60). The International Journal of Psychology and Psychological Therapy; 8: 171-181.

[24] Craúovan D.I. (2011). Fundamentele testării psihologice [Bases of Psychological Testing]. Timiúoara: Editura Eurostampa. ISBN 978-606-569-205-3.

[25] Tamparo C., Lewis M. (2011). Diseases of the Human Body. Philadelphia, PA: F.A. Davis Company. P. 459. ISBN 9780803625051.

[26] Gleicher N. (2018). Expected advances in human fertility treatments and their likely translational consequences. J Transl Med.; 16(1): 149.

[27] Benksim A., Elkhoudri N., Addi R.A., Baali A., and Cherkaoui M. (2018). Difference between Primary and Secondary Infertility in Morocco: Frequencies and Associated Factors. Int J Fertil Steril.; 12(2): $142-146$.

[28] Zhou Z., Zheng D., Wu H., Li R., Xu S., Kang Y., Cao Y., Chen X., Zhu Y., Xu S., Chen Z.J., Mol B.W., and Qiao J. (2018). Epidemiology of infertility in China: a population-based study. BJOG.; 125(4): 432-441.

[29] Rashidi B.H. et al. (2017). Behavioral Defensive Mechanism in Infertile Couples; 6(Issue 3): 49-54.

[30] Namdar A., Naghizadeh M.M., Zamani M., Yaghmaei F., and Sameni M.H. (2017). Quality of life and general health of infertile women. Health Qual Life Outcomes. 15(1): 139.

[31] Ghasemi M., Kordi M., Asgharipour N., Esmaeili H., and Amirian M. (2017). The effect of a positive reappraisal coping intervention and problem-solving skills training on coping strategies during waiting period of IUI treatment: An RCT. Int J Reprod Biomed (Yazd).; 15(11): 687-696.

[32] Pasha H., Basirat Z., Faramarzi M., and Kheirkhah F. (2018). Comparative Effectiveness of Antidepressant Medication versus Psychological Intervention on Depression Symptoms in Women with Infertility and Sexual Dysfunction. Int J Fertil Steril.; 12(1): 6-12.

[33] Poddar S., Sanyal N., and Mukherjee U. (2014). Psychological profile of women with infertility: A comparative study. Ind Psychiatry J.; 23(2):117-26.

[34] Whitehead K. (2016). Motherhood as a Gendered Entitlement: Intentionality, "Othering," and Homosociality in the Online Infertility Community. Can Rev Sociol.; 53(1): 94-122. 
[35] Dada O.A., Faloye B.B., and Dumet D.J. (2012). Phenotypic variability of some morphological traits among Canavalia species. Scholarly Journal of Agricultural Science; 2(5). 87-93.

[36] Duthie E.A., Cooper A., Davis J.B., Sandlow J., Schoyer K.D., Strawn E., and Flynn K.E. (2017). Priorities for family building among patients and partners seeking treatment for infertility. Reprod Health. 14(1):52.
[37] Sormunen T., Aanesen A., Fossum B., Karlgren K., and Westerbotn M. (2018). Infertility-related communication and coping strategies among women affected by primary or secondary infertility. J Clin Nurs.; 27(1-2): e335-e344.

[38] Li X.Q., Sun C.F., and Guo M. (2017). Benefits of nursing care service in the assisted reproduction clinic to self-cyclemanagement and self-efficiency of infertility patients. Zhonghua Nan Ke Xue.; 23(6):536-539. 